\title{
La cuestión de la posible potestad general de las conferencias episcopales
}

\author{
The Issue of the Possible General Legal Authority \\ of Episcopal Conferences
}

\begin{abstract}
Antonio VIANA
Profesor Ordinario de Organización Eclesiástica

Universidad de Navarra. Facultad de Derecho Canónico. Pamplona

orcid 0000-0002-9857-1500

aviana@unav.es
\end{abstract}

Resumen: La conferencia episcopal es una institución que ha atravesado distintas etapas desde su origen en el siglo XIX. Actualmente, en conexión con la doctrina de la sinodalidad de la Iglesia se plantea si se debe reconocer a las conferencias episcopales una potestad general sobre las diócesis de la nación. En este trabajo se estudian los argumentos a favor y en contra de esta posibilidad, y se recuerda la importancia de la función «prevalentemente» consultiva de la conferencia episcopal.

Palabras clave: Conferencia episcopal, Colegialidad, Sinodalidad, Colegios consultivos.
Abstract: The Episcopal conference is an institution that has gone through different stages since its origins in the nineteenth century. At present, given the doctrine of the synodality of the Church, there is some discussion of whether Episcopal conferences should be recognized as having general authority over the dioceses of the nation. This paper addresses the arguments for and against this possibility, and the importance of the «predominantly» consultative function of the Episcopal conference is recalled.

Keywords: Episcopal Conference, Collegiality, Synodality, Consultative Bodies. 


\section{LAS DISTINTAS ETAPAS EN LA EVOLUCIÓN INSTITUCIONAL DE LAS CONFERENCIAS EPISCOPALES}

$\square$ obre las conferencias episcopales se ha escrito mucho en los últimos decenios por parte de teólogos y canonistas de diferentes naciones y escuelas. Han sido repetidamente tratadas las cuestiones principales de orden teológico y canónico que tienen que ver con la institución. Parecería entonces superfluo añadir algo a lo que ya se ha estudiado e incluso debatido tantas veces. Sin embargo, la autoridad eclesiástica no ha dejado de promover desde el Sínodo de los obispos de 1985 un estudio más amplio, e incluso el papa Francisco, como luego recordaré, considera insuficiente el esfuerzo de explicitación realizado hasta hoy.

No debe extrañar esta necesidad de reflexión y actualización de una institución tan importante para la Iglesia contemporánea como la conferencia episcopal. De hecho, se pueden distinguir algunas etapas desde su origen en el siglo XIX hasta su consolidación en los siglos XX y XXI.

Las conferencias episcopales surgieron oportunamente en la vida de la Iglesia. En las reuniones periódicas de los obispos belgas desde 1830, y de otros países europeos más tarde, como Alemania, Austria e Italia, destacaba la necesidad de formular criterios compartidos desde los que hacer frente y dar respuesta a los problemas comunes de la época. Eran causa de preocupación principal, aunque no exclusiva, las dificultades que la Iglesia encontraba en aquellos países, como consecuencia de la difusión de una ideología política liberal, contraria a la plena presencia de la jerarquía de la Iglesia en la vida pública. A la muerte del papa León XIII en 1903, esas reuniones de obispos, conventus episcoporum, reconocidas ya y promovidas por la Santa Sede, existían también fuera del continente europeo ${ }^{1}$.

A pesar de que el CIC de 1917 no reguló en profundidad las conferencias episcopales nacionales, estableció, sin embargo, en el c. $292 \$ 1$, que el arzobispo metropolitano debía procurar que se celebraran en el ámbito de la provincia eclesiástica reuniones de obispos al menos quinquenales, y «examinar en común lo que deba hacerse para promover el bien de la religión en sus diócesis y preparar los asuntos que hayan de ser tratados en el futuro concilio provincial».

${ }^{1}$ Cfr. G. Feliciani, Le conferenze episcopali, Bologna 1974, 16 ss. 
Pero fue sobre todo el Concilio Vaticano II el acontecimiento que habría de servir de gran impulso a las conferencias episcopales. No es que el Concilio las instituyera, pues existían ya en no pocos países; pero el Vaticano II las recomendó, las situó en un contexto doctrinal enmarcado en la solicitud episcopal por el bien de las distintas Iglesias particulares y les impuso un régimen bastante detallado para el ejercicio de sus competencias jurídicas ${ }^{2}$. Un régimen jurídico especial que en su planteamiento de fondo fue conservado años más tarde por el CIC de 1983, y que tiene una especial relevancia para identificar el status jurídico de las conferencias episcopales.

Como dice Manzanares, en el Vaticano II tuvo lugar una verdadera «transformación sustancial» de las conferencias episcopales: «De encuentros no oficiales, en autoridad encuadrada en el derecho constitucional de la Iglesia; de asambleas voluntarias, en coetus obligatorios en cuanto a su existencia y participación en ellos; de reuniones heterogéneas en su configuración y composición, en conventus esencialmente homogéneos; de organismos dotados exclusivamente de autoridad moral, en institutos capaces de adoptar decisiones jurídicamente vinculantes, aunque limitadas a materias específicas y bajo condiciones ciertamente rigurosas» ${ }^{3}$.

Esta primera etapa del desarrollo de las conferencias episcopales comprende, por tanto, desde su origen en el siglo XIX hasta su extensión a toda la Iglesia, como instrumento que puede favorecer la función pastoral de los obispos en las diversas naciones y continentes.

Una nueva etapa comprendería los años posteriores a la celebración del Vaticano II, con dos momentos especiales. El primero se abrió con ocasión de la preparación y promulgación del CIC de 1983; el segundo consistió en la celebración de la asamblea extraordinaria del Sínodo de los obispos en 1985. Ambos momentos resultaron de gran interés.

Al Código de 1983 le correspondió encauzar el desarrollo de las conferencias episcopales, a la luz de la eclesiología y las determinaciones del Vaticano II. Para ello estableció en los cc. 447-459 una regulación detallada de la naturaleza, composición, organización y potestad jurídica de las conferencias. Es interesante precisar que en los proyectos preparatorios del texto, había sido previsto un elenco de funciones más amplio del que fue aprobado finalmente

2 Cfr. especialmente, const. Lumen gentium, n. 23 y el texto del decr. Christus Dominus, nn. 37-39.

3 J. MANZANARes, Las conferencias episcopales en el nuevo Código de Derecho Canónico, en G. BARBERINI (a cura di), Raccolta di scritti in onore di Pio Fedele, I, Perugia 1984, 513-514. 
en el texto definitivo ${ }^{4}$. También debe destacarse que no fue atribuida una competencia jurídica general a la conferencia, ya que, por una parte, el c. 447 estableció que los obispos se valen de la conferencia para ejercer unidos «algunas funciones pastorales» y, por otra parte, el CIC optó por establecer una lista de decisiones jurídicas correspondientes a la conferencia episcopal, antes que un reconocimiento general de una facultad para legislar sobre cualquier materia que corresponda a la potestad de los obispos en sus diócesis. En efecto, el CIC mantuvo la previsión del Concilio Vaticano II de una regulación jurídica estricta del ejercicio de la potestad de la conferencia, reconociendo, al mismo tiempo, la posibilidad de que la conferencia pueda legislar en los casos previstos por el derecho común, o bien por delegación de la Santa Sede mediante un mandato especial ${ }^{5}$.

Pero el CIC de 1983, preocupado por establecer normas sobre la función legislativa de las conferencias, no reguló el ejercicio de la función docente de los obispos en ellas. De tal manera que la previsión contenida en el canon 753 sobre el magisterio colegial de los obispos, situado en el libro III del CIC sobre el munus docendi de la Iglesia, quedó sin ulterior desarrollo en los cánones del libro II dedicados a las conferencias episcopales.

Esta laguna del CIC fue percibida por la asamblea extraordinaria del Sínodo de los obispos, celebrada en 1985 para conmemorar el vigésimo aniversario de la clausura del Vaticano II. En realidad, apenas dos años después de la promulgación del CIC, el Sínodo planteó un examen a fondo de la experiencia posconciliar. Un examen que partía ante todo del reconocimiento del valor e importancia («utilidad y necesidad») de la actividad de las conferencias episcopales, pero que puso de relieve también la necesidad de profundizar en la solución de algunos problemas que se habían presentado. Entre ellos: un excesivo intervencionismo de las conferencias de al-

${ }^{4}$ Cfr. G. FelicianI, Il potere normativo delle conferenze episcopali nella comunione ecclesiale, en Comunione e disciplina ecclesiale, Atti del XXII Congresso dell'Associazione Canonistica Italiana, Aosta, 10-13 settembre 1990, Città del Vaticano 1991, 90; A. PAGAN, Conferenze episcopali. I lavori del coetus «de sacra Hierarchia» (1966-1983), Venezia 2012, 23 y 257. A juicio de Giorgio Feliciani (cfr. ibid., 90), esta restricción del número de competencias inicialmente previstas por los proyectos de 1972-1977, fue debida con toda probabilidad a la firme resistencia opuesta por no pocos obispos, preocupados por las limitaciones a su función pastoral que comportaba la mayor autoridad de las conferencias episcopales, lo que provocó que a partir del Schema Codicis de 1980, distintas competencias antes atribuidas a las conferencias no fuesen reservadas a la Santa Sede, sino reconocidas a favor de los obispos diocesanos.

${ }^{5}$ Cfr. c. $455 \$ 1$ del CIC. 
gunos países en la vida de las diócesis, condicionando la autonomía de los obispos; una cierta centralización de actividades pastorales, unida a la proliferación de documentos doctrinales, no siempre publicados y respaldados por la asamblea plenaria de los obispos del país, sino por distintas comisiones internas. Se veía también como un problema que las conferencias no siempre reflejaran en su actividad la necesaria unidad de los obispos entre sí y con la Santa Sede ${ }^{6}$. La relatio finalis del Sínodo advertía, en efecto, que $\ll$ las conferencias episcopales en su modo de proceder deben tener presente el bien de la Iglesia, es decir, el servicio de la unidad y la responsabilidad inalienable de cada obispo hacia la Iglesia universal y hacia su Iglesia particular» ${ }^{7}$.

Pero más que la solución de problemas concretos, el Sínodo de 1985 alentó una reflexión profunda sobre la condición teológica y canónica de las conferencias episcopales:

«Puesto que las conferencias episcopales son tan útiles, más aún necesarias, en el actual trabajo pastoral de la Iglesia, se desea un estudio de su status teológico, sobre todo para que la cuestión de su autoridad doctrinal sea expuesta de manera más clara y profunda, teniendo presente lo que se dice en el Concilio, en el decreto Christus Dominus, n. 38, y en el Código de Derecho Canónico, cc. 447 y 753» ${ }^{8}$.

Como consecuencia de esta exhortación del Sínodo de 1985, tuvo lugar un amplio debate en el que participaron destacados teólogos y canonistas, reflejado en numerosas publicaciones ${ }^{9}$. Paralelamente, por encargo del Papa Juan Pablo II, fue preparado en la Congregación para los obispos un documento de trabajo, titulado Le conferenze episcopali, fechado el 1-VII-1987, y que se dividía en dos partes principales: una dedicada al estatuto teológico y otra al estatuto jurídico de las conferencias. El documento fue enviado a consulta

\footnotetext{
${ }^{6}$ Incluso Manzanares, entusiasta defensor del papel de las conferencias, reconoce, por ejemplo, que las reacciones de los episcopados a la enc. Humanae Vitae de Pablo VI «parecían comprometer la unidad de doctrina en la Iglesia»: J. MANZANARES, Las conferencias episcopales. Entre la inquietud y la esperanza, en F. R. AZNAR GIL (ed.), Magister canonistarum. Estudios con motivo de la concesión al prof. dr. D. Urbano Navarrete, S.I., del doctorado honoris causa, Salamanca 1994, 91.

${ }^{7}$ Asamblea extraordinaria del sínodo de los obispos de 1985. Relación Final, II. C. 5, en Documentos del Concilio Vaticano II. Constituciones, decretos, declaraciones, BAC, Madrid ${ }^{43} 1991$, apéndice II, 712.

${ }^{8}$ Relatio finalis, C.8.b: ibid., 714.

${ }^{9}$ Ofrezco una selección bibliográfica actualizada al final de este estudio.
} 
a las conferencias episcopales y en su parte final contenía un cuestionario para facilitar las respuestas ${ }^{10}$.

Por lo que se sabe, el documento de 1987 recibió numerosas críticas y la publicación quedó aplazada ${ }^{11}$. De hecho, pasaron once años hasta que en 1998 fue promulgado por Juan Pablo II el motu proprio Apostolos suos ${ }^{12}$.

Del m.p. Apostolos suos cabe destacar dos aportaciones principales. La primera, una amplia fundamentación de las conferencias episcopales como institución. No en vano el documento pontificio lleva este subtítulo: «Sobre la naturaleza teológica y jurídica de las conferencias de los obispos». Después de una introducción histórica, el motu proprio trata ampliamente de la unión colegial entre los obispos y sitúa las conferencias episcopales en el marco de la colegialidad episcopal.

La segunda aportación de Apostolos suos al desarrollo institucional de las conferencias episcopales fue la regulación de su función docente, cuestión en la que existía una laguna que merecía ser colmada, según hemos recordado al tratar del Sínodo de 1985. La solución que establece el motu proprio consiste básicamente en aplicar al ejercicio del munus docendi de la conferencia los requisitos que ya había establecido el c. 455 del CIC para la publicación de decretos generales. De este modo, Apostolos suos distingue básicamente entre las funciones doctrinales o de enseñanza cristiana de las conferencias episcopales y el magisterio auténtico, que es el que ejercen los obispos revestidos de una especial autoridad recibida de Jesucristo y que, por tanto, exige una adhesión religiosa especial de los fieles ${ }^{13}$. La distinción no es superflua, pues no todo lo que dicen o publican los obispos, individualmente o reunidos en conferencias episcopales, tiene la misma fuerza moral vinculante, ya sea por la naturaleza misma del asunto del que se hayan ocupado, ya porque su intención no haya consistido en ejercer formalmente la función de magisterio. Pues bien, para que las declaraciones doctrinales de las conferencias puedan ser consideradas legítimos actos colegiales de magisterio auténtico de los obispos

${ }^{10}$ Cfr. CONGREgación PARA LOS OBISPOS, Instrumentum laboris «Le conferenze episcopali», sullo «status» teologico e giuridico delle conferenze episcopali, 1-VII-1987, en Enchiridion Vaticanum, X, Bologna 1989, 1286-1305.

${ }^{11}$ Cfr. J. I. ARRIETA, Le conferenze episcopali nel motu proprio «Apostolos suos», Ius Ecclesiae 11 (1999) 170; K. WinTERKAMP, Die Bischofskonferenz zwischen «affektiver» und «effektiver Kollegialität», Münster 2003, 510.

12 JuAn Pablo II, m.p. Apostolos suos, 21-V-1998, AAS 90 (1998) 641-658.

${ }_{13}$ Cfr. m.p. Apostolos suos, n. 22. 
y puedan ser publicadas en nombre de la conferencia, deben ser aprobadas por todos los obispos miembros, o, si esto no es posible, en reunión plenaria al menos por dos tercios de los prelados que pertenecen a la conferencia con voto deliberativo, y con la exigencia, además, de que el texto sea revisado por la Sede apostólica antes de su publicación ${ }^{14}$. Esta exigencia de que sólo la reunión plenaria de los obispos es sujeto de eventuales actos de magisterio auténtico colegial, se completa con la prohibición de que tal potestad de magisterio pueda ser delegada por la plenaria en favor de comisiones episcopales más reducidas u otros organismos de la conferencia ${ }^{15}$.

La promulgación de Apostolos suos vino a reflejar una nueva etapa en la evolución de las conferencias episcopales como institución jurídica de la Iglesia. El documento constituye una respuesta avalada por un amplio periodo de reflexión por parte de teólogos y canonistas, en el que no faltaron consultas al episcopado mundial. El documento de Juan Pablo II se presenta como una explicitación «de los principios teológicos y jurídicos básicos sobre las conferencias episcopales (...), con el fin de ayudar a establecer una praxis de las mismas conferencias episcopales teológicamente fundada y jurídicamente segura ${ }^{16}$.

La promulgación de Apostolos suos ha constituido un nuevo elemento de un proceso doctrinal; una nueva fase en la que se reconoce la necesidad y utilidad pastoral de las conferencias episcopales, su fundamento en la doctrina de la co-

${ }^{14}$ Cfr. m.p. Apostolos suos, IV, art. 1. Esta exigencia, por parte de Apostolos suos, de la unanimidad o de una mayoría tan cualificada es cuestionada por Joseph Komonchak. El autor observa que algunos de los documentos del Vaticano II no habrían podido ser aprobados con estas mayorías tan exigentes (cfr. J. A. KomONCHAK, On the authority of Bishop's Conferences, America 12-IX1998 , 10). Pero se pueden recordar las amplísimas mayorías con las que fueron aprobados los documentos del Vaticano II, en algunos casos muy cercanas a la unanimidad. Dos documentos conciliares son de especial importancia para las conferencias episcopales: la const. Lumen gentium y el decr. Christus Dominus. Sobre un total de 2.156 votantes, Lumen gentium fue aprobada con 2.151 votos a favor y solo 5 en contra; mientras que Christus Dominus recibió 2.319 placet, 2 non placet y un voto nulo (cfr. los datos en la obra citada supra, nota 7, p. 6). Por lo tanto, Apostolos suos no plantea una exigencia imposible de alcanzar. Además, en el caso de un concilio ecuménico los obispos constituyen con el Papa la autoridad suprema de la Iglesia, mientras que una conferencia episcopal no goza de la potestad de un concilio para imponer sus enseñanzas o decisiones a todos los obispos del territorio, salvo que medie una regulación del derecho pontificio. La exigencia de fuertes mayorías o incluso de la unanimidad no es solo una manera de estimular el necesario consenso, sino también una forma de promover el respeto de la autonomía de la Iglesia particular, en los casos (excepcionales) en que el obispo diocesano considere en conciencia que no puede adherirse a la opinión mayoritaria de los demás miembros de la conferencia.

15 Cfr. m.p. Apostolos suos, IV, art. 2.

${ }^{16}$ M.p. Apostolos suos, I, n. 7. 
legialidad episcopal y la necesidad de que su actividad sea oportunamente regulada por normas jurídicas, que coordinen debidamente la presencia y virtualidad de las conferencias en la vida de la Iglesia con la potestad de los obispos en sus Iglesias particulares y las competencias propias de la Sede apostólica.

\section{UNA ETAPA NUEVA PROMOVIDA POR EL PAPA FRANCISCO.}

\section{LA CONFERENCIA EPISCOPAL A LA LUZ DE LA SINODALIDAD DE LA IGLESIA}

Según la evolución que antes ha sido recordada, el m.p. Apostolos suos no es un simple documento más, vinculado a una eclesiología superable, válida solamente para un contexto histórico en franca evolución. Detrás de esta ley pontificia hay mucha experiencia histórica acumulada a lo largo de un proceso en el que han confluido la actividad y opinión de los obispos, el estudio de los especialistas y el discernimiento del magisterio pontificio.

De todos modos, no solo no debe excluirse la apertura a nuevas transformaciones en una institución tan importante para la actuación de la jerarquía episcopal en los distintos países, sino que el propio papa Francisco ha querido llamar la atención sobre esta posibilidad en uno de los documentos más importantes de su pontificado: la exhortación apostólica Evangelii gaudium, de 24-XI-2013. En el n. 32 de esta exhortación dice el Papa, al tratar de la «pastoral en conversión»:

«El Concilio Vaticano II expresó que, de modo análogo a las antiguas Iglesias patriarcales, las conferencias episcopales pueden "desarrollar una obra múltiple y fecunda, a fin de que el afecto colegial tenga una aplicación concreta" [const. Lumen gentium, n. 23]. Pero este deseo no se realizó plenamente, por cuanto todavía no se ha explicitado suficientemente un estatuto de las conferencias episcopales que las conciba como sujetos de atribuciones concretas, incluyendo también alguna auténtica autoridad doctrinal [cfr. JuAN PABLO II, Motu proprio Apostolos suos, 21V-1998, AAS 90 (1998) 641-658]. Una excesiva centralización, más que ayudar, complica la vida de la Iglesia y su dinámica misionera».

Aparte del paralelismo que Evangelii gaudium establece entre los patriarcados y las conferencias episcopales, a propósito de la aplicación del affectus collegialis o espíritu colegial que debe inspirar el trabajo conjunto de los obispos, destaca en el texto citado el deseo de una mayor responsabilidad de las conferencias episcopales en lo que se refiere a sus «atribuciones concretas» y a su «autoridad doctrinal». La cita que hace Evangelii gaudium del m.p. Apos- 
tolos suos es genérica; es decir, no se refiere a un pasaje concreto del documento de Juan Pablo II. En este sentido cabe interpretar que el papa Francisco advierte expresamente de la vigencia de Apostolos suos, al tiempo que anima a profundizar en una mayor descentralización a favor de las conferencias episcopales ${ }^{17}$. Las palabras del Papa de ninguna manera deben considerarse una desautorización del camino recorrido en los años posteriores al Sínodo de 1985, como si el esfuerzo realizado no hubiera sido eficaz. En este sentido quizás la clave de interpretación de Evangelii gaudium n. 32 se encuentre en el adverbio «suficientemente» que emplea el texto. Se habría hecho mucho pero no lo suficiente. Por eso, sería necesario avanzar en la reflexión teológica y canónica aprovechando el trabajo realizado hasta hoy.

Pero los nuevos vientos que soplan a favor de la responsabilidad pastoral de las conferencias episcopales deben verse en un contexto más amplio. Por una parte, la institución de la conferencia episcopal se inscribe en la doctrina eclesiológica de la colegialidad de los obispos, a la luz de la enseñanza del Concilio Vaticano II. En esta línea el m.p. Apostolos suos confirma ampliamente ese contexto eclesiológico. Pero, por otra parte, la reflexión sobre la conferencia episcopal también resulta estimulada por la reflexión sobre la sinodalidad en la Iglesia.

En efecto, el papa Francisco leyó el día 17-X-2015 un discurso con ocasión del cincuenta aniversario de la institución de Sínodo de los obispos ${ }^{18}$. En aquella ocasión el Pontífice quiso referirse a la sinodalidad como un proceso de escucha y colaboración recíprocas entre pastores y pueblo fiel, el Colegio episcopal y el obispo de Roma que permita un «caminar juntos», según la inspiración del Espíritu Santo. Todos los fieles están llamados a participar en el

${ }^{17}$ Según información de la Santa Sede, en una de las recientes reuniones del consejo de cardenales que asesora al papa Francisco en la reforma de la curia romana, la celebrada entre el 12 y el 14 de junio de 2017, se trató de «la posibilidad de transferir algunos poderes de los dicasterios romanos a los obispos locales o a las conferencias episcopales, con un espíritu de sana descentralización. Por ejemplo, la transferencia del dicasterio para el clero a la conferencia episcopal para el examen y la aprobación de: ordenar sacerdote a un diácono permanente no casado; nuevo matrimonio de un diácono permanente viudo; demanda de acceso a la ordenación sacerdotal de un diácono permanente viudo»: Sala Stampa della Santa Sede, Briefing del Director de la Oficina de Prensa sobre la XX reunión de los cardenales consejeros, 14-VI-2017, n. 0411. Sobre la descentralización, cfr. también el n. 16 de Evangelii gaudium, donde el papa Francisco afirma: «Tampoco creo que deba esperarse del magisterio papal una palabra definitiva o completa sobre todas las cuestiones que afectan a la Iglesia y al mundo. No es conveniente que el Papa reemplace a los episcopados locales en el discernimiento de todas las problemáticas que se plantean en sus territorios. En este sentido, percibo la necesidad de avanzar en una saludable "descentralización”».

${ }^{18}$ El texto se puede consultar en www.vatican.va, en la sección de discursos pontificios. 
«compromiso de edificar una Iglesia sinodal». Es un camino -seguía diciendo Francisco en aquel importante discurso- que se realiza principalmente en tres niveles estructurales.

El primer nivel de la sinodalidad se lleva a cabo en las Iglesias particulares, a través de los organismos colegiales que prevé el derecho: algunos de ellos reservados al presbiterio de la diócesis, como el consejo presbiteral, el colegio de consultores y el cabildo de canónigos; pero otros abiertos a la participación también de laicos, como el sínodo diocesano y el consejo pastoral.

El segundo nivel «es el de las provincias y de las regiones eclesiásticas, de los concilios particulares y, de modo especial, de las conferencias episcopales [cfr. CIC, cc. 431-459]. Debemos reflexionar para realizar todavía más, a través de estos organismos, las instancias intermedias de la colegialidad, quizás integrando y actualizando algunos aspectos del antiguo orden eclesiástico. El deseo del Concilio de que tales organismos contribuyen a acrecentar el espíritu de la colegialidad episcopal todavía no se ha realizado plenamente. Estamos a mitad de camino, en una parte del camino. En una Iglesia sinodal, como ya afirmé, "no es conveniente que el Papa reemplace a los episcopados locales en el discernimiento de todas las problemáticas que se plantean en sus territorios. En este sentido, percibo la necesidad de avanzar en una saludable descentralización" [Evangelii gaudium, n. 26 y cfr. ibid., n. 32]».

Por fin, el último nivel es el de la Iglesia universal. Además de la función propia del Sucesor de Pedro y del concilio ecuménico, la institución del sínodo de los obispos, representando al episcopado católico, tiene la virtualidad de expresar la colegialidad episcopal (collegialitas affectiva) dentro de una Iglesia sinodal.

Como puede verse, según el pensamiento pontificio, las categorías de la sinodalidad y la colegialidad episcopal se distinguen, pero están estrechamente relacionadas ${ }^{19}$. En la sinodalidad se refleja la vocación que cada fiel recibe en el bautismo y en la confirmación para cooperar activamente en la obra común. En este sentido, la sinodalidad tiene como base fundamental la corresponsabilidad y participación de todos los fieles en la misión de la Iglesia, aspecto que fue afirmado con vigor por el Concilio Vaticano II, con un acento

${ }^{19}$ Sobre el contenido de la sinodalidad es útil consultar L. BALDISSERI (ed.), A cinquant'anni dall'«Apostolica Sollicitudo». Il Sinodo dei Vescovi al servizio di una Chiesa sinodale, Città del Vaticano 2016, libro de actas de un seminario organizado en 2016 por la Secretaría del sínodo de los obispos. Cfr. mi nota bibliográfica: Sinodalidad y derecho canónico, Estudios eclesiásticos 92 (2017) 683-701. 
nuevo en el marco histórico de los concilios ecuménicos ${ }^{20}$. En cambio, la colegialidad episcopal se refiere solamente a la jerarquía, a los obispos en cuanto miembros del colegio que sucede al Colegio apostólico y que con el Romano pontífice constituye la autoridad suprema en la Iglesia.

Las conferencias episcopales participan de la doctrina de la colegialidad episcopal, no evidentemente en el sentido de una acción estricta del Colegio de los obispos, ya que ésa solo puede tener lugar mediante la actividad conjunta de todos los obispos con el Papa para toda la Iglesia, y no basta una parte del Colegio episcopal, como en el caso de los obispos de una nación. Así, el m.p. Apostolos suos afirma: «En otras palabras, "la colegialidad episcopal en sentido propio y estricto, pertenece sólo a todo el Colegio episcopal que, como sujeto teológico, es indivisible". Esto es así por voluntad expresa del Señor ${ }^{21}$. Pero la colegialidad episcopal constituye también un vínculo de comunión especial, de carácter sacramental, que expresa una vocación de los obispos a cooperar conjuntamente al servicio pastoral de las Iglesias de una misma nación o territorio, como testimonia la historia de la Iglesia con los concilios particulares y hoy con las mismas conferencias episcopales. En estas conferencias el vínculo colegial entre los obispos promueve un espíritu real de colaboración conjunta y coordinada ${ }^{22}$.

$\mathrm{Al}$ tiempo que en las conferencias episcopales se refleja la colegialidad episcopal como expresión continuada de la colaboración de los obispos, estos colegios contribuyen en el ámbito interdiocesano al desarrollo de la sinodalidad. Como hemos recordado, en el discurso papal del 2015 se viene a subrayar que la realización de «una Iglesia sinodal» exige la promoción de las «ins-

${ }^{20} \mathrm{El}$ apostolado y el servicio a la Iglesia no están reservados a la jerarquía, sino que son tarea de todos los fieles, porque están basados en los sacramentos del bautismo y de la confirmación. En efecto, «existe una auténtica igualdad entre todos en cuanto a la dignidad y a la acción común a todos los fieles para la edificación del Cuerpo de Cristo»: const. Lumen gentium, n. 32. Cfr. también ibid., n. 30 y decr. Apostolicam actuositatem, nn. 2 y 3 .

21 M.p. Apostolos suos, n. 12. La cita interna de Apostolos suos se refiere a JuAn Pablo II, Discurso a la Curia Romana, 20-XII-1990, 6, AAS 83 (1991) 744.

22 Cfr. aquí especialmente los nn. 22 y 23 de la const. Lumen gentium. «La acción colegial tomada en sentido estricto implica la actividad de todo el colegio juntamente con su cabeza sobre toda la Iglesia. Su expresión nítida se tiene en el concilio ecuménico (...). Son distintas de esta primera colegialidad, tomada en sentido estricto, diversas realizaciones parciales [del principio teológico de la colegialidad episcopal] que son verdaderamente signo e instrumento de afecto colegial: el sínodo de los obispos, las conferencias episcopales, la curia romana, las visitas ad limina, etc.»: Asamblea extraordinaria del sínodo de los obispos de 1985. Relación Final, II. C. 4, e, 17, ed. cit., 711 y 712 . 
tancias intermedias» colegiales como las conferencias episcopales. De este modo se haría posible que la fase de discernimiento y valoración dentro del proceso sinodal, después de haber consultado a los fieles, pudiera realizarse con mayor eficacia.

\section{3. ¿COMPETENCIA GENERAL DE LAS CONFERENCIAS EPISCOPALES?}

El principio de la sinodalidad inspiraría una ampliación de la potestad de los organismos episcopales interdiocesanos a través de un proceso de oportunas descentralizaciones. Según este planteamiento, las conferencias episcopales deberían ser reforzadas en su potestad y competencias. Lo mismo cabría decir a propósito de la colaboración entre otros organismos episcopales, con una mayor descentralización en favor de las distintas agrupaciones de obispos en ámbitos territoriales continentales.

Ahora bien, un proceso jurídico de descentralización puede tener lugar de dos maneras. Puede realizarse a través de la atribución de distintas competencias mediante el instrumento de la delegación de potestades por la Santa Sede a las conferencias episcopales. En realidad, esta vía está prevista ya por el derecho común de la Iglesia latina en el c. $455 \$ 1$ del CIC, que alude a la institución canónica del «mandato especial» como un modo de ampliar el ejercicio de la potestad jurídica de la conferencia episcopal ${ }^{23}$. Además, una segunda manera de arbitrar la descentralización consiste en el reconocimiento de una potestad general de la conferencia episcopal sobre las diócesis del territorio (casi siempre, el ámbito de una nación). De este modo, la conferencia episco-

23 «La conferencia episcopal puede dar decretos generales tan sólo en los casos en que así lo prescriba el derecho común o cuando así lo establezca un mandato especial de la Sede apostólica, otorgado motu proprio o a petición de la misma conferencia»: c. $455 \$ 1$ del CIC de 1983. Este canon distingue entre la potestad de la conferencia episcopal por derecho común y por mandato especial de la Sede apostólica. En este último caso se trata de una delegación de potestad, como lo prueba la misma distinción del canon y el uso de una expresión («mandato especial») que clásicamente se emplea para aludir a la delegación de potestad (cfr. además, entre otros, los cc. $203 \$ 1$ del CIC de 1917 y 133 del CIC de 1983 sobre el mandato de delegación). En distintos lugares del CIC se habla del mandato especial para referirse a la delegación de potestad, como, por ejemplo, en los cc. $134 \$ 3$ y $479 \$ \$ 1$ y 2 del CIC sobre la potestad ordinaria vicaria de los vicarios generales y episcopales, a la que se puede añadir un mandato especial por parte del obispo. Sobre esta concreta cuestión cfr. H. MüLler, Die rechtliche Stellung des Diözesanbischofs gegenüber Generalvikar und Bischöfsvikar, Archiv für katholisches Kirchenrecht 153 (1984) 408, y P. Platen, Mandato especial, en J. Otaduy - A. Viana - J. Sedano (eds.), Diccionario general de derecho canónico, Thomson Reuters-Aranzadi, Cizur Menor 2012, vol. 5, 264-266. 
pal se transformaría en un colegio regional de obispos con potestad legislativa general, frente a las competencias especiales que hoy le reconoce el derecho. Esta posibilidad plantea cuestiones de fondo que merecen ser atendidas, examinando los argumentos a favor y en contra.

El primer argumento es de orden eclesiológico y de alguna manera ya ha sido descrito. Si la Iglesia debe progresar en un camino de verdadera sinodalidad, es necesario un reforzamiento de las instancias intermedias entre el Romano Pontífice y las Iglesias particulares, también en lo que se refiere al ejercicio del gobierno sobre las diócesis. De este modo la conferencia episcopal sería un instrumento para articular una verdadera agrupación de Iglesias particulares ${ }^{24}$. Un instrumento central y necesario para la expresión de la comunión de las Iglesias particulares en una nación. La conferencia episcopal tendría protagonismo en el proceso sinodal de las Iglesias particulares, pues le correspondería liderar una fase de discernimiento y valoración, después de que los obispos hubieran consultado a los fieles de las distintas diócesis del país sobre distintas cuestiones de la vida de la Iglesia.

Este mayor protagonismo de la conferencia episcopal vendría aconsejada por la «socialización» (rectius: globalización) de la vida moderna y el desarrollo de las comunicaciones, que estimulan la colaboración estable de los obispos entre sí y una mayor inculturación; es decir, la adaptación del mensaje evangélico a las circunstancias de las personas y los lugares concretos ${ }^{25}$.

También se podría alegar un paralelismo de la conferencia episcopal con otros organismos episcopales y en concreto con los concilios particulares. Los concilios particulares son una institución venerable, de gran importancia en la historia de la Iglesia en tantos países. Su potestad legislativa general, sobre la provincia eclesiástica o un territorio más amplio, es reconocida tranquilamente por el derecho común de la Iglesia latina. No se ve entonces qué razón se opondría a que el mismo reconocimiento se extendiera a la competencia de la conferencia episcopal. Por otra parte, también podría o debería establecerse un paralelismo con los sínodos de las Iglesias orientales en comunión con Roma, cuya potestad general no se discute.

${ }^{24}$ Cfr. A. Borras, Évolutions soubaitables en matière de synodalité sur le plan des «instances intermédiaires», en L. BALDISSERI (ed.), A cinquant'anni dall'«Apostolica Sollicitudo» (nota 19), 284-294 especialmente.

25 Sobre «socialización» e inculturación, cfr. brevemente, J. MANZANARES, Reflexiones sobre el documento «Estatuto teológico y jurídico de las conferencias episcopales», Revista española de derecho canónico 46 (1989) 195. 
La cuestión de la competencia general de la conferencia episcopal es ante todo una cuestión prudencial, que debe ser decidida según las circunstancias de la vida de la Iglesia y de las consecuencias que comporte. No es principalmente una cuestión que dependa de la solución de específicos problemas teológicos, como son la prioridad o no de la Iglesia universal sobre la Iglesia particular, o el fundamento exclusivamente sacramental o no de la potestad de los obispos. Evidentemente estas y otras cuestiones teológicas son importantes y tienen consecuencias también para la configuración jurídica de las conferencias episcopales. Pero, a mi modesto juicio, ni la competencia general de la conferencia es consecuencia necesaria de la comunión de las Iglesias particulares, ni la potestad especial es fruto característico de una eclesiología universalista ${ }^{26}$.

Un argumento en contra de la potestad general de las conferencias episcopales es que semejante reconocimiento exigiría una reforma del derecho constitucional. En efecto, esa opción se aleja claramente no sólo del derecho positivo, sino también de las previsiones del mismo Concilio Vaticano II, que estableció una competencia especial de las conferencias episcopales al configurar su capacidad normativa ${ }^{27}$. El Concilio Vaticano II eligió un Mittelweg, un camino intermedio entre las propuestas de los que querían una conferencia episcopal sin poderes efectivos y quienes abogaban ya por una competencia general ${ }^{28}$. Ese razonable camino intermedio se ha mantenido siempre en la legislación posconciliar. Evidentemente, el derecho sigue a la vida y las normas canónicas siempre están abiertas a reformas y derogaciones; pero si se quiere reformar aquella orientación descrita, debería abrirse un proceso de amplia consulta a los obispos y no solo a un grupo reducido de expertos.

Además, no es fácil compartir el planteamiento de una instancia intermedia con potestad general sobre las Iglesias particulares del territorio. En

${ }^{26}$ Jorge Miras ha llamado la atención sobre los problemas metodológicos que derivan de centrar excesivamente las cuestiones relativas a las conferencias episcopales en el ser de la Iglesia, antes que en el de su misión; en este sentido, la pretensión de establecer un fundamento teológico de las conferencias episcopales para deducir después su necesaria naturaleza jurídica, presenta un riesgo de distorsión. Cfr. J. MIRAS, Fundamentación y naturaleza jurídica de las conferencias episcopales: sugerencias para una reflexión sobre el método, en La Synodalité. La participation au gouvernement dans l'Église, Actes du VIIe Congrès international de Droit canonique, Paris 21/28-IX1990, publicadas en L'Année Canonique, (h. s.) 1992, vol. II, 529-534.

27 Cfr. c. 455 del CIC y Juan Pablo II, m.p. Apostolos suos, IV, arts. 1-4; decr. Christus Dominus, n. 38. 4. La conferencia episcopal tiene potestad decisoria y normativa en los casos previstos por el derecho común o también cuando recibe delegación de la Santa Sede.

${ }^{28}$ Cfr. G. FeLICIANI, Il potere normativo delle conferenze episcopali nella comunione ecclesiale (nota 4), 87. 
la reflexión sobre la naturaleza de las conferencias episcopales de las últimas décadas, se ha pasado de una percepción un tanto idealista de la conferencia episcopal como instrumento principal en la articulación de la comunión de las Iglesias, a otra visión mucho más adecuada a la configuración histórica de este colegio. No solo porque aquella idea fuera muy debilitada después de un periodo de reflexión abierto desde el CIC de 1983 y la celebración del sínodo de los obispos extraordinario de 1985, hasta el m.p. Apostolos suos de Juan Pablo II en 1998; sino también porque la conferencia episcopal es básicamente un complemento de la función pastoral de los obispos en sus diócesis. La conferencia sirve y complementa las tareas de los obispos en sus Iglesias particulares, pero no es ni debería configurarse, a mi juicio, como un órgano con potestad normativa general sobre las cuestiones que correspondan a los obispos diocesanos, es decir, aquellas que no estén reservadas a la Santa Sede u a otra autoridad ${ }^{29}$. Si esto fuera así, sería difícil evitar la transformación del obispo en un oficio ejecutor administrativo de las decisiones de la conferencia episcopal, cuyo titular se limitaría prácticamente a la celebración de la liturgia y a la función profética ${ }^{30}$. Una transformación que podría producir en la práctica la separación de los tria munera Christi y una clara limitación extrínseca de la sacra potestas que corresponde al obispo en su Iglesia particular ${ }^{31}$. Volveré sobre esta importante cuestión en la parte final de este estudio.

A mi juicio, los documentos magisteriales y jurídicos vigentes no justifican la concepción de la conferencia episcopal como expresión necesaria, central y protagonista de la comunión de las Iglesias particulares en una nación.

${ }^{29}$ Cfr. c. $381 \S 1$ del CIC de 1983.

30 En efecto, una competencia general fácilmente transformaría el sentido de la conferencia episcopal: de una ayuda al obispo en su diócesis pasaría a convertirse en un órgano alternativo en el ejercicio de la potestad episcopal. Cfr. G. FELICIANI, Il potere normativo delle conferenze episcopali nella comunione ecclesiale (nota 4), 91; A. PAGAN, Conferenze episcopali (nota 4), 259.

31 Péter Szabó es partidario de un mayor fortalecimiento de la potestad de las conferencias episcopales sin excluir la atribución de una potestad legislativa general, sobre la base de la experiencia de los sínodos de las Iglesias orientales en comunión con Roma. Pero este autor explica oportunamente que en la práctica esto exige serias medidas que hagan posible la participación, la consulta mutua y el debate riguroso. En los sínodos orientales esto viene facilitado porque no tienen una composición excesivamente numerosa, mientras que no ocurre siempre lo mismo en las conferencias episcopales latinas. Como dice Szabó, «si una conferencia está compuesta por trescientos miembros, es simplemente imposible que sea escuchada la voz de todos ellos»: Possibili sviluppi della sinodalità: proposizioni orientali, en L. BALDISSERI (ed.), A cinquant'anni dall' «Apostolica Sollicitudo», 130. Tal vez debería ser aplicada con más frecuencia la posibilidad de las regiones eclesiásticas, prevista por el c. 433 del CIC. 
Más bien queda situada como un complemento colegial a la capitalidad ordinaria y propia de los obispos en sus diócesis.

Otro argumento en contra de la posible competencia general de las conferencias episcopales se refiere a su inutilidad o falta de realismo, al menos en bastantes casos. En efecto, hay conferencias episcopales que ni siquiera han querido o han podido legislar sobre las materias en las que son competentes según el $\mathrm{CIC}^{32}$. Es difícil adivinar por qué razones ha sucedido tal cosa, pero seguramente esta indefinición tenga que ver no pocas veces con la falta de organización y medios personales que soporten la actividad de las conferencias ${ }^{33}$. Se comprueba que una descentralización plena de la potestad no es deseable para todas las conferencias, pues seguramente algunas de ellas no estarían en condiciones de asumir una plena responsabilidad ni una actividad normativa permanente. Las conferencias episcopales son muy diversas entre sí por historia, organización, número de obispos miembros, contexto eclesiológico, cultural y político. Mejor sería aprovechar el instrumento de la potestad delegada y reconocer a las que así lo pidieran competencias nuevas, en lugar de dar a todas una potestad que no querrían ni podrían asumir en todos los casos.

En este sentido, un sistema de competencias jurídicas especiales es más realista y defiende frente al peligro de un aumento excesivo de la burocracia eclesiástica. La referencia a esta amenaza burocrática (burocratica ratio), se encuentra expresamente en el n. 18 de Apostolos suos, donde se subraya que «las conferencias episcopales, con sus comisiones y oficios, existen para ayudar a los obispos y no para sustituirlos». En efecto, un colegio de obispos con potestad general sobre un territorio deberá ser dotado de los medios personales, financieros y estructurales que garanticen suficientemente las tareas ordinarias al servicio de las Iglesias locales, más allá de los periodos de reunión de los obispos en las distintas asambleas. No parece que ésta sea una solución conveniente para toda la Iglesia. El crecimiento incontrolado de actividades y estructuras es en la Iglesia especialmente peligroso, porque ese incremento no siempre se ve con claridad y frecuentemente quiere fundamentarse en nobles razones pastorales. El excesivo crecimiento de la organización produce como efectos típicos el oscurecimiento de las relaciones personales y de la iniciativa apostólica. El obispo que preside una Iglesia particular es ante todo servidor

32 Cfr. G. FeLiciani, Il potere normativo delle conferenze episcopali nella comunione ecclesiale (nota 4), 91.

33 La cuestión fue ya planteada durante la preparación del CIC de 1983: cfr. A. PAGAN, Conferenze episcopali (nota 4), 168. 
de la grey concreta que se le ha confiado y para la que tiene misión canónica. No deben debilitarse las relaciones personales de comunión entre pastores y fieles, en beneficio de una atención de las tareas colegiales que pueda resultar excesiva o desproporcionada, a causa del trabajo y el tiempo que requieren. Cuando esto sucede, se hacen más difíciles esas relaciones y la comunicación con los fieles de la diócesis, comenzando por los miembros del presbiterio ${ }^{34}$.

Cuando se establece el paralelismo con los concilios particulares, al que antes me refería, no siempre se tiene en cuenta una diferencia fundamental. Los concilios particulares (provinciales o regionales-plenarios) tienen una importancia histórica que está fuera de duda y el derecho les atribuye potestad legislativa sobre las Iglesias particulares del territorio, para «establecer cuanto parezca oportuno para el incremento de la fe, la organización de la actividad pastoral común, el orden de las buenas costumbres y la observancia, establecimiento o tutela de la disciplina eclesiástica común», y siempre respetando el derecho eclesiástico universal y con la revisión de los decretos por parte de la Sede apostólica ${ }^{35}$. Pero esa potestad legislativa general es, al mismo tiempo, extraordinaria y ocasional. En efecto, los concilios particulares no se convocan regularmente, ya que el derecho común no contiene ya indicaciones sobre la periodicidad de su celebración ${ }^{36}$. Sin embargo, en el caso de las conferencias episcopales la configuración institucional es diversa. No sólo por su composición, que en las conferencias está reservada a los obispos y pastores equipara-

${ }^{34}$ El papa Francisco ha criticado la figura de los «obispos de aeropuerto», lo que no quiere decir evidentemente que no deban participar responsablemente en las conferencias episcopales y otros organismos colegiales a los que sean llamados. Cfr., por ejemplo, el n. 3 del discurso a los nuevos obispos leído el 19-IX-2013, en www.vatican.va, en la sección de discursos pontificios.

${ }^{35}$ CIC, c. 445. Cfr. c. 446.

${ }^{36}$ En la evolución histórica de los concilios particulares se manifestó el problema de lo que Orlandis ha denominado «la imposible periodicidad conciliar»: J. ORLANDIS, Función histórica y eclesiológica de los concilios particulares, en La Synodalité (nota 26), vol. I, 298. En efecto, desde que el Concilio de Nicea ordenara en el siglo IV la celebración del concilio provincial dos veces al año, la praxis de establecer la periodicidad conciliar fue mantenida todavía en el año 1215 por la const. $6^{\text {a }}$ del Concilio IV de Letrán (que dispuso la celebración de concilios provinciales una vez al año). Sin embargo, esta determinación no fue cumplida en la práctica. Por eso en siglos posteriores la disciplina fue mitigada, de manera que, según las disposiciones de Martín V, León X (siglos XV y XVI, respectivamente) y el propio Concilio de Trento, el Concilio provincial debía celebrarse cada tres años. Con todo, a la vista de las dificultades para observar estas disposiciones (cfr. ibid., 295), el CIC de 1917 amplió mucho los plazos, señalando en el c. 283 que el concilio provincial debía celebrarse al menos cada veinte años. Pero ni siquiera bastó esta ampliación para que la norma fuera observada habitualmente en las diversas provincias eclesiásticas. Por eso, el CIC de 1983 ha renunciado finalmente a establecer plazo alguno para la convocatoria y celebración de los concilios particulares. 
dos, mientras que los concilios particulares admiten a diversos fieles ${ }^{37}$, sino también por la regularidad de su convocatoria. Las conferencias episcopales son colegios permanentes de convocatoria regular y no meramente ocasional ${ }^{38}$. Esta configuración comporta que la incidencia práctica del ejercicio de su potestad sea mucho mayor que en el caso de los concilios. Lo que en un concilio ocasionalmente convocado resulta natural y necesario, en un colegio permanente produciría seguramente una excesiva centralización normativa, en perjuicio de la potestad de los obispos en sus respectivas diócesis.

En cuanto al paralelismo con los sínodos orientales, cabe señalar que ha sido no pocas veces contestado desde las coordenadas propias del derecho canónico oriental ${ }^{39}$. Además, las instituciones orientales supradiocesanas del estilo de los patriarcados y los sínodos son considerados por documentos pontificios una participación en la autoridad suprema, por lo que sería difícil su comparación eficaz con las conferencias episcopales, que son formas de cooperación episcopal en el nivel propio de las Iglesias particulares ${ }^{40}$. Por su parte, el m.p.

${ }^{37}$ Compárense los cc. 443 y 450 del CIC de 1983.

38 Significativamente el c. 447 del CIC se refiere a la conferencia episcopal como institutum permanens, y, por su parte, el c. $449 \$ 2$ dispone que la conferencia episcopal legítimamente erigida tiene personalidad jurídica ipso iure.

39 Un amplio estudio sobre esta cuestión en P. SzaBó, Il Sinodo episcopale della Chiesa patriarchale in raffronto alla Conferenza episcopale: possibilità e limiti di una «osmosi» tra i due istituti, en G. RUYSSEN (ed.), Il diritto orientale a cinquant'anni dal Concilio Vaticano II, Atti del Simposio di Roma, 23-25 aprile 2014, Roma 2016, 335-370.

40 En las Iglesias orientales en comunión con Roma el patriarca (y también por equiparación el arzobispo mayor, y en cierta medida el metropolita sui iuris) es cabeza de otros obispos en la propia Iglesia, es decir, en la comunión regional de Iglesias particulares que forman la Iglesia sui iuris patriarcal, arzobispal mayor o metropolitana sui iuris. Esta posición peculiar de potestad sobre otros obispos es considerada como una participación en responsabilidades propias de la autoridad suprema, por derecho eclesiástico, según expresa la const. ap. Sacri canones, de 18-X-1990, mediante la que Juan Pablo II promulgó el texto del CCEO. Allí se afirma que el patriarca y los sínodos participan canónicamente de la suprema autoridad de la Iglesia: «Patriarchae et synodi iure canonico supremae Ecclesiae auctoritatis participes sunt», AAS 83 (1990) 1037. Cabe destacar también la afirmación contenida en la exh. ap. de JuAn Pablo II, Pastores Gregis, de 16-X-2003, AAS 96 (2004) 825-924, n. 61: «Todo aquel que ejerce una potestad supraepiscopal y supralocal en las Iglesias orientales como los patriarcas y los sínodos de los obispos de las Iglesias patriarcales participa de la autoridad suprema que el Sucesor de Pedro tiene sobre toda la Iglesia y ejerce dicha potestad respetando, además del primado del Romano Pontífice (cfr. cc. 76; 77 CCEO), la función de cada obispo, sin invadir el campo de su competencia ni limitar el libre ejercicio de sus propias funciones». Cfr. sobre esta cuestión, I. ŽUŽEK, Un Codice per una varietas Ecclesiarum, en S. GHERRO (ed.), Studi sul Codex Canonum Ecclesiarum Orientalium, Padova 1994, 4 y 5; del mismo autor: Presentazione del Codex Canonum Ecclesiarum Orientalium, en IDEM, Understanding the Eastern Code, Roma 1997, 127, donde se detiene sobre la cuestión del fundamento del poder supraepiscopal intermedio que se ejerce en las Iglesias orientales; también: Alcune note circa la struttura delle Chiese orientali, ibid., 137; E. EID, La synodalité dans la tradition orientale, en La Synodalité, cit., vol. I, 255. 
Apostolos suos subraya expresamente la distinción entre los sínodos orientales y las conferencias episcopales, salvo la analogía que se advierte a propósito de las asambleas de jerarcas de varias Iglesias sui iuris, reguladas por el CCEO en el c. 322, que tienen una regulación semejante a la dispuesta para las conferencias episcopales latinas en lo que se refiere al ejercicio jurídico de la potestad ${ }^{41}$.

\section{Profundizar EN La Naturaleza «PREDominantemente» CONSULTIVA DE LAS CONFERENCIAS}

Si la atribución universal de potestad jurídica general a las conferencias episcopales plantea más problemas que soluciones y podría resultar imprudente, cabe preguntarse cómo responder al deseo expresado por el papa Francisco de un mayor dinamismo y responsabilidad de las conferencias. A mi juicio, en lo que corresponde al derecho canónico, una de las posibles respuestas consistiría en una mayor estimación de la función consultiva de estos colegios, en la línea del estímulo del Pontífice de reforzar «el espíritu de la colegialidad episcopal», como él decía en el citado discurso del 2015.

En efecto, un aspecto histórico primordial de las conferencias episcopales, que no debería oscurecerse, es su naturaleza jurídica consultiva, lo que no excluye que en ocasiones puedan ejercer verdadera potestad canónica deliberativa.

Las conferencias episcopales son verdaderos colegios de la organización jerárquica de la Iglesia. Esta afirmación debe ser sostenida con toda claridad, a pesar de que sobre esta cuestión ha existido cierta confusión, debida a que el término colegialidad referido a la acción de los obispos «no es unívocamente significativo» ${ }^{42}$. En efecto, algunos autores, temerosos de que mediante la invocación del principio teológico de la colegialidad episcopal se atribuyeran a las conferencias episcopales funciones que solamente son propias del Colegio episcopal con su cabeza que es el Papa, han negado incluso que las conferencias episcopales reflejen propiamente ese principio teológico. Según este planteamiento, la colegialidad episcopal no podría predicarse de las conferencias episcopales, a causa de su incapacidad para representar el Colegio episcopal

${ }^{41}$ Cfr. m.p. Apostolos suos, nota 1 del documento. Sobre las asambleas del c. 322 del CCEO, cfr. A. VIANA, Estructuras personales y colegiales de gobierno. Con referencia especial al problema de la movilidad bumana y de la diáspora de los católicos orientales, Folia Canonica 7 (2004) 22 y 23.

42 A. BettetinI, Collegialità, unanimità e «potestas». Contributo per uno studio sulle conferenze episcopali alla luce del m.p. «Apostolos suos», Ius Ecclesiae 11 (1999) 499, nota 17. 
para toda la Iglesia ${ }^{43}$. Incluso se ha llegado a decir que el término colegio aplicado a las conferencias episcopales sería admisible solo en un sentido analógico y teológicamente impropio, porque impropia sería su relación con la colegialidad episcopal para toda la Iglesia ${ }^{44}$. Sin embargo, en estos años se ha ido aclarando, como ya recordé más arriba, que la colegialidad episcopal significa un vínculo especial de comunión, característico del episcopado como grado supremo del sacramento del orden, que además del servicio a toda la Iglesia con el Papa, comporta también un trabajo conjunto de los obispos en ámbitos particulares, al servicio de las Iglesias relacionadas por especiales vínculos históricos y nacionales. En este sentido, las conferencias episcopales son aptas para reflejar un vínculo de colegialidad, del que ya había hablado el Vaticano II en Lumen gentium 23, distinguiéndolo, pero no separándolo completamente, del servicio que corresponde al Colegio episcopal para toda la Iglesia ${ }^{45}$.

Sigue siendo necesario distinguir la colegialidad episcopal como principio teológico de la colegialidad entendida en sentido jurídico, sin perjuicio de la relación entre ambos principios. Si no se tiene en cuenta esta distinción, podría declararse teológicamente impropio lo que es canónicamente adecuado ${ }^{46}$.

${ }^{43}$ Cfr. el status quaestionis que resume J. ForNÉs, Autoridad y competencias de la conferencia episcopal. Un comentario al m.p. «Apostolos suos» de 21 de mayo de 1998, Ius canonicum 39 (1999) 747-753; J. HAMER, La responsabilité collégiale de chaque évêque, Nouvelle revue théologique 105/5 (1983) 643 y 646. Arrieta subraya que según Apostolos suos, las conferencias episcopales no son expresión de la colegialidad del episcopado en sentido propio, porque no pueden considerarse instancias regionales del poder o autoridad que reside en el Colegio episcopal, que como tal es único e indivisible; de ahí que él prefiera hablar de una «actividad colectiva» de la conferencia en la que se actúa el espíritu colegial entre los obispos: J. I. ARRIETA, Le conferenze episcopali nel motu proprio «Apostolos suos» (nota 11), 177, 184 y 185.

${ }^{44}$ Así, la Comisión Teológica Internacional: «Si se aplican a éstas [a las conferencias episcopales] los términos "colegio", "colegialidad", "colegial" se usan en sentido analógico y teológicamente impropio»: COMmissio THEOlOGICA INTERNATIONALIS, Themata selecta de ecclesiologia, Documenta 13, Roma 1985, 35. Cfr. J. R. VILLAR, La naturaleza de las conferencias episcopales y la carta Apostolos suos, Scripta theologica 31 (1991/1) 119 y 120, 137.

45 Cfr. m.p. Apostolos suos, nn. 9-14. Cfr. A. ANTón, La lettera apostolica «Apostolos suos» di Giovanni Paolo II, La civiltà cattolica 3566 (1999/1) 128, y también IDEM, Le conferenze episcopali: un aiuto ai vescovi, ibid. (1999/1) 335.

${ }^{46}$ Cfr. aquí el planteamiento de J. R. VILlar, Fundamentos teológicos de las conferencias episcopales, Anuario de derecho canónico 6 (2017) 125, y 129-130, donde está ausente la distinción entre colegialidad jurídica y colegialidad episcopal. Sobre esta distinción, cfr., brevemente, H. SCHMITZ, Bischofskonferenz und Partikularkonzil. Rechtsinstitutionen unterschiedlicher Natur, Struktur und Funktion, en H. MüLleR - H. J. POTTMEYER (eds.), Die Bischofskonferenz. Theologischer und jurisdischer Status, Düsseldorf 1989, 192 y, más ampliamente, la monografía clásica de W. Aymans, Das synodale Element in der Kirchenverfassung, München 1970, especialmente 190-226; también, K. WinTERKaMP, Die Bischofskonferenz (nota 11), 69 ss. 
El dato de que las conferencias episcopales no reflejan lo que solo es propio de los obispos con el Papa para toda la Iglesia, no excluye su fundamento en la colegialidad episcopal y que actúen canónicamente como verdaderos colegios. El directorio para los obispos Apostolorum successores, de 2004, habla ya abiertamente de los «actos colegiales de gobierno» que produce ocasionalmente la conferencia episcopal ${ }^{47}$.

Dentro de los colegios de la organización eclesiástica se pueden distinguir los colegios deliberativos de los consultivos. Es una clasificación que se emplea para distinguir la diversa eficacia jurídica que el derecho atribuye al acto o voluntad colegial ya formada ${ }^{48}$.

En efecto, los colegios de la organización jerárquica de la Iglesia se reúnen, deliberan, adoptan decisiones, expresan una voluntad unitaria más allá de las diversas opiniones de los miembros. Se habla así de la voluntad o acto colegial (c. 119 del CIC), que tiene consistencia propia según el derecho canónico, de modo que es diferente de un simple acto colectivo y de la mera suma de actos individuales. Pero esa voluntad o acto colegial unitario puede tener efectos jurídicos bien diversos: puede constituir simplemente una deliberación interna, que no se exprese externamente, al referirse tan solo a los miembros del colegio; o bien puede trasladarse al tráfico jurídico externo como un juicio referido a la actividad del gobernante; o incluso la voluntad colegial puede llegar a ser ella misma una decisión, un mandato vinculante para terceros. Es en este sentido, es decir, según la eficacia jurídica del acto o voluntad colegial, como puede hablarse de colegios consultivos y deliberativos.

Los colegios consultivos emiten juicios o dictámenes sobre las cuestiones que les propone el gobernante o sobre aquellas en las que el derecho establece su intervención. Se caracterizan por suministrar elementos de juicio a la autoridad competente para adoptar la decisión de gobierno definitiva. Estos colegios consultivos están previstos en todos los niveles de la organización eclesiástica (el consejo presbiteral, el colegio de consultores diocesano), y cumplen un importante papel en el desarrollo de la función de gobierno.

47 La conferencia episcopal «es importante para fortalecer la comunión entre los obispos y promover la acción común en un determinado territorio (...). Le son confiadas algunas funciones pastorales propias, que ejerce a través de actos colegiales de gobierno, y es la sede adecuada para la promoción de múltiples iniciativas pastorales comunes para el bien de los fieles»: CONGREGACIÓN PARA LOS OBISPOS, dir. Apostolorum successores, 22-II-2004, n. 23/d.

48 Sobre la colegialidad en sentido jurídico remito a mis estudios citados al final de este trabajo, a los que puede añadirse, para la distinción entre colegios consultivos y deliberativos, Organización del gobierno en la Iglesia, Pamplona ${ }^{3} 2010$, cap. IV: «los colegios». 
En cambio, los colegios deliberativos tienen reconocida la capacidad no ya de emitir juicios, sino verdaderas declaraciones de voluntad, decisiones con efectos definitivos y directos para los destinatarios; es decir, sin mediación de una autoridad a la que corresponda la decisión definitiva, que no es otra que el propio colegio deliberativo. Es el caso, por ejemplo, de un decreto general administrativo publicado por una congregación de la curia romana con potestad vicaria del Papa, la sentencia de un tribunal colegial, las decisiones jurídicas de los concilios particulares y de las conferencias episcopales en algunos supuestos, etc. En los colegios deliberativos, por tanto, la voluntad colegial tiene eficacia jurídica inmediata y definitiva, obviamente siempre que se hayan cumplido las reglas sobre formación del acto colegial y éste pueda incluirse dentro de las competencias jurídicas del colegio.

Esta mención (en realidad, simple recordatorio) de la naturaleza predominantemente consultiva de las conferencias episcopales puede causar cierta perplejidad. En efecto, la regulación de los colegios consultivos en el derecho canónico parece ser insuficiente ya para los colegios diocesanos en los que intervienen sacerdotes y laicos, como el sínodo, el consejo presbiteral o el consejo pastoral diocesano y parroquial. Las normas de todos estos organismos se preocupan de advertir que tienen solamente voto consultivo (votum tantum consultivum $)^{49}$. Si esta expresión parece ya cautelosa en relación con la participación colegial de los fieles en general, a fortiori sonaría demasiado restrictiva si se aplica a la actividad de los obispos.

Es verdad que la determinación legal de la competencia consultiva de un colegio de la organización eclesiástica marca una clara limitación, al excluir la potestad deliberativa, es decir, la eficacia jurídica directa e inmediata ad extra de las decisiones colegiales. Sin embargo, la función consultiva en la Iglesia significa algo distinto del voto consultivo en la sociedad civil y no se limita simplemente al ejercicio del poder. Expresa más bien el desarrollo de un proceso participativo en la misión de la Iglesia, un discernimiento compartido de las exigencias de la acción misionera, al tiempo que se preparan y maduran las futuras decisiones ${ }^{50}$. La función consultiva resulta de gran impor-

${ }^{49}$ Cfr. los cc. $466,500 \$ 2,514 \$ 1$ y $536 \$ 2$ del CIC, referidos respectivamente al sínodo diocesano, consejo presbiteral, consejo pastoral diocesano y consejo pastoral parroquial. Sobre la cuestión, cfr. el estudio de A. BORRAS, «Votum tantum consultivum». Les limites ecclésiologiques d'une formule canonique, Didaskalia 45 (2015) 145-162; especialmente, 152 ss.

${ }^{50}$ Cfr. A. BorRas, «Votum tantum consultivum», 161 y 162 . En la literatura sobre la cuestión es conocida la siguiente opinión de Eugenio Corecco: «Con il voto consultivo l'ordinamento giuri- 
tancia en la Iglesia, cuando es aplicada conforme a su alto significado pastoral y apostólico.

Pero, además, los obispos están llamados no sólo a ser protagonistas personales del gobierno, sino también a participar colegialmente en la preparación de las decisiones. Con un matiz importante: en el marco de la organización jerárquica de la Iglesia el principio colegial no sustituye, sino que complementa, el principio capital o personal. La capitalidad de los obispos en sus diócesis, conforme a la tradición del episcopado monárquico, debe ser respetada y promovida por cualquier organización intermedia entre el Romano pontífice y los obispos ${ }^{51}$. Los órganos que operan canónica y pastoralmente en el ámbito interdiocesano o supradiocesano, como los arzobispos metropolitanos, los concilios particulares o las mismas conferencias episcopales, ven regulada su actividad por el derecho pontificio dentro de ciertos límites ${ }^{52}$.

Esto responde a que debe quedar a salvo «la potestad que por institución divina tiene el obispo en su Iglesia particular» ${ }^{53}$. En efecto, en una consideración teológica, para que un obispo vea limitada su potestad en la Iglesia particular que preside por otras instancias episcopales intermedias, o para verse obligado a seguir una decisión que no comparte, es necesaria la mediación de la autoridad pontificia, de acuerdo con el derecho canónico. Como el acuerdo unánime entre los obispos no siempre resulta posible, corresponde solamente al derecho pontificio proteger la comunión de los pastores y regular las condiciones de la imposición de las decisiones por una mayoría de obispos. En

dico della Chiesa esprime (...) la posizione di tutti gli altri fedeli (laici e chierici) chiamati strutturalmente a contribuire alla formulazione del giudizio di fede di coloro che hanno la responsabilità di esprimerlo come giudizio comune, vincolante per tutti. (...) Essendo il sacerdozio comune, con il "sensus fidei" di tutti questi fedeli, primario rispetto a quello ministeriale -nel senso che quest'ultimo esiste solo in funzione della realizzazione del sacerdozio comune- il Vescovo e il clero, nella formazione del loro giudizio in ordine al governo della Chiesa particolare non possono prescindere dallo stesso, anche se le modalità concrete di consultazione possono storicamente cambiare»: E. CORECCO, Sinodalitá e partecipazione nell'esercizio della «potestas sacra», en A. CIANI - G. DiURNI (eds.), Esercizio del potere e prassi della consultazione, Atti dell'VIII Colloquio Internazionale Romanistico-Canonistico, Roma 1991, 83-85.

51 Sobre el principio capital y el episcopado monárquico en la organización eclesiástica, cfr. O. CONDORELLI, «Unum corpus, diversa capita». Modelli di organizzazione e cura pastorale per una «varietas ecclesiarum» (secoli XI-XV), Roma 2002, 25-45, 141-186; A. VIANA, Oficio capital, en J. OTADUY A. Viana - J. SEDANo (eds.), Diccionario general de derecho canónico (nota 23), vol. V, 684-686.

52 En el caso de los concilios particulares, su potestad legislativa general viene compensada por el hecho de su convocatoria ocasional y el límite del respeto a la legislación universal de la Iglesia, además de las condiciones establecidas por el c. 446 del CIC. Cfr. también el c. 445.

53 M.p. Apostolos suos, n. 3. 
efecto, los demás obispos, por sí mismos, es decir, sin intervención de la Sede apostólica, «no tienen el poder de imponer la obediencia de su decisión o la adhesión interna a su enseñanza a otro hermano en el episcopado o a los fieles de la Iglesia particular que él preside ${ }^{54}$. Esta afirmación no prejuzga el fundamento de la potestad de las conferencias episcopales. Aunque sean instituidas por la Sede apostólica y no por la libre voluntad de los obispos que las componen, la intervención instituyente del derecho pontificio se basa en la potestad sagrada de los obispos recibida por el sacramento del orden y la misión canónica. De este modo, la potestad propia de las conferencias episcopales no es meramente delegada ni vicaria de la Sede apostólica, sino que es un poder episcopal, colegial e interdiocesano, regulado en su ejercicio por el derecho pontificio. El m.p. Apostolos suos afirma en concreto que «la eficacia vinculante de los actos del ministerio episcopal ejercido conjuntamente en el seno de las conferencias episcopales y en comunión con la Sede apostólica deriva del hecho de que ésta ha constituido dichos organismos y les ha confiado, con fundamento en la potestad sagrada de cada uno de los obispos, ciertas funciones» ${ }^{55}$.

Esta mediación pontificia puede concretarse en una atribución de potestad deliberativa general o especial a aquellas organizaciones supradiocesanas, como sucede en el caso de la regulación establecida para los concilios particulares y las conferencias episcopales. También puede concretarse en una regulación más clara de su actividad consultiva, perfectamente compatible con posibles capacidades decisorias.

En el caso de las conferencias episcopales su función consultiva es tradicional, en un doble sentido. Por una parte, la conferencia episcopal ayuda a la formación del juicio de los propios obispos miembros en tantos aspectos. Es un foro especial de diálogo y consulta estables con los demás obispos de tantas cuestiones que afectan al gobierno de sus diócesis. Por otra parte, la conferencia es también destinataria y sujeto colegial de consultas por parte de la Santa Sede. Esta intervención de las conferencias episcopales, al dar su opinión sobre cuestiones que afecten a la Iglesia universal y a las Iglesias particulares del territorio, está prevista por el CIC en distintas materias; por ejemplo, en lo que se refiere al nombramiento de obispos ${ }^{56}$. Pero, además, es un crite-

\footnotetext{
54 A. Miralles, Le conferenze dei vescovi: lettura teologica del motu proprio «Apostolos suos», en IDEM, «Pascete il gregge di Dio». Studi sul ministero ordinato, Roma 2002, 135.

55 M.p. Apostolos suos, n. 13. La cursiva es mía.

56 Cfr. c. $377 \$ \$ 2$ y 3 del CIC.
} 
rio general expresamente previsto en las normas generales de la curia romana. En efecto, la const. ap. Pastor bonus dispone expresamente: «Han de favorecerse unas relaciones frecuentes con las Iglesias particulares y con los organismos episcopales, pidiendo su opinión cuando se trate de preparar documentos de mayor importancia, que tengan carácter general» ${ }^{57}$. El hecho de que este criterio haya sido descuidado en algunos casos recientes aconseja recordar su vigencia y su importancia para una verdadera corresponsabilidad de las conferencias en distintos aspectos de la vida de la Iglesia ${ }^{58}$.

Que la conferencia episcopal sea un colegio consultivo no impide evidentemente, como hemos discutido en estas páginas, que en ocasiones pueda y deba actuar como verdadero colegio deliberativo; es decir, con capacidad de tomar decisiones con eficacia jurídica ad extra directa e inmediata, dentro de las condiciones establecidas por el derecho, principalmente en el c. 455 del CIC. Sin embargo, aparte de la producción de numerosos actos administrativos singulares (como son distintos nombramientos y aprobaciones), la función normativa o legislativa de las conferencias es poco frecuente y se da en circunstancias especiales previstas por el derecho. La actividad ordinaria de estos colegios tiene que ver mucho más con la consulta, y exige un aprendizaje de las reglas de la colegialidad interna.

Es necesario dar importancia al voto consultivo en la Iglesia y en las conferencias episcopales. Es algo que conecta con los valores propios de la colegialidad episcopal, que pide ante todo tratar y reflexionar conjuntamente sobre los temas comunes y proponer medidas generales o concretas. En la práctica, el estilo colegial llevará a cada obispo a manifestar libre y francamente sus opiniones en las reuniones de la conferencia, sin dejarse llevar del aislamiento ni de una actitud individualista. En efecto, junto a la necesidad de afirmar la responsabilidad personal del obispo diocesano en su Iglesia particu-

57 JUAN PABLo II, const. ap. Pastor bonus, de 28-VI-1988, sobre la curia romana, AAS 80 (1988) $841-912$, art. $26 \$ 1$.

58 En los últimos años se han promulgado algunas leyes pontificias que afectan de manera significativa al ejercicio de la potestad de los obispos. Sobre todo el m.p. Mitis iudex, que reformó profundamente el proceso canónico declarativo de la nulidad del matrimonio (AAS 107 [2015] 958970, donde se promulga también el m.p. Mitis et misericors Iesus, de la misma fecha, aplicable a las Iglesias orientales: ibid., 946-957). Pero también puede aludirse al m.p. del papa FRANCISCO, Come una madre amorevole, 4-VI-2016, sobre la posibilidad de remoción de los obispos en casos de negligencia grave o muy grave en las funciones de su oficio (AAS 108 [2016] 715-717). No consta que el procedimiento preparatorio de ambas normas haya incluido la consulta a los obispos (si bien la primera de ellas fue prevista en general por el sínodo episcopal del 2014). 
lar, conforme a la tradición católica del episcopado monárquico, también es necesario subrayar la responsabilidad colegial del obispo. Él no puede aislarse en su diócesis, sino que debe abrirse a la colegialidad, hacia la colaboración con los demás obispos, por una parte, y hacia la consulta habitual a los presbíteros y demás fieles en su Iglesia particular. La autonomía del obispo en su diócesis no es un justificante para el aislamiento ni para el autoritarismo individual, sino precisamente una garantía para vivir la colegialidad y la consulta. En las reuniones de la conferencia episcopal, lo normal será que cada miembro siga el criterio de la mayoría, «sin obstinarse en las propias posturas ${ }^{59}$. Es el criterio tradicional, canónico y moral, que dice también, para los casos en los que el obispo piense que no debe seguir la opinión mayoritaria, que deberá valorar seriamente su actitud en conciencia, considerando todas las circunstancias y las consecuencias de su eventual voto negativo ${ }^{60}$. Más allá del voto positivo o negativo, la búsqueda del consenso es siempre una señal clara de verdadera comunión, sin excluir incluso la unanimidad, por más que no siempre sea posible y existan diferencias de opinión legítimas y respetables.

59 Dir. Apostolorum Successores, n. 29 e.

${ }^{60}$ Cfr. ibid., y con carácter general, c. $127 \$ \$ 2,2^{\circ}$ y 3 del CIC. Insiste en este aspecto A. BorRAS, «Votum tantum consultivum» (nota 49), 156 ss. 


\section{Bibliografía}

ANTón, A., La lettera apostolica «Apostolos suos» di Giovanni Paolo II, La civiltà cattolica 3566 (1999/1) 119-132.

—, Le conferenze episcopali: un aiuto ai vescovi, ibid. (1999/1) 332-344.

ARrIETA, J. I., Conferenze episcopali e vincolo di comunione, Ius Ecclesiae 1 (1989) $3-22$.

—, Le conferenze episcopali nel motu proprio «Apostolos suos», Ius Ecclesiae 11 (1999) 169-191.

Aymans, W., Das synodale Element in der Kirchenverfassung, Max Hueber Verlag, München 1970.

—, Geistlose Bischofskonferenz? Kritik an einem Beitrag von Ladislas Örsy über «Die Bischofskonferenzen und die Macht des Geistes», Archiv für katholisches Kirchenrecht 169 (2000) 3-19.

BetTetini, A., Collegialità, unanimità e «potestas». Contributo per uno studio sulle conferenze episcopali alla luce del m.p. «Apostolos suos», Ius Ecclesiae 11 (1999) 493-509.

BORRAS, A., «Votum tantum consultivum». Les limites ecclésiologiques d'une formule canonique, Didaskalia 45 (2015) 145-162.

—, Évolutions soubaitables en matière de synodalité sur le plan des «instances intermédiaires», en L. BALDISSERI (ed.), A cinquant'anni dall'«Apostolica Sollicitudo». Il Sinodo dei Vescovi al servizio di una Chiesa sinodale, Libreria Editrice Vaticana, Città del Vaticano 2016, 263-296.

Bunge, A. W., Juan Pablo II y las conferencias episcopales: comunión y colegialidad, The person and the challenges 3 (2013) 43-89.

Del Pozzo, M., Puntualizzazioni di diritto costituzionale sulla collegialità episcopale «affettiva» ed «effettiva», Ius Ecclesiae 29 (2017) 113-134.

EID, E., La synodalité dans la tradition orientale, en La Synodalité. La participation au gouvernement dans l'Église, Actes du VIIe Congrès international de Droit canonique, Paris 21/28-IX-1990, publicadas en L'Année Canonique, (h. s.) 1992, vol. I, 249-264.

ERDÖ, P., Zur verschiedenen Natur der einzelnen Kompetenzen der Bischofskonferenz. Kanonistische Anmerkungen über den Apostolischen Brief «Apostolos suos», en K. T. Geringer - H. SCHMiTz (Hrsg.), Communio in Ecclesiae Mysterio: Festschrift für Winfried Aymans zum 65. Geburtstag, EOS, St. Ottilien 2001, 83-95.

FELICIANI, G., Le conferenze episcopali, Il Mulino, Bologna 1974. 
—, Il potere normativo delle conferenze episcopali nella comunione ecclesiale, en Comunione e disciplina ecclesiale, Atti del XXII Congresso dell'Associazione Canonistica Italiana, Aosta, 10-13 settembre 1990, Libreria Editrice Vaticana, Città del Vaticano 1991, 87-93.

ForNÉs, J., Autoridad y competencias de la conferencia episcopal. Un comentario al m.p. «Apostolos suos» de 21 de mayo de 1998, Ius canonicum 39 (1999) 733-759.

GHIRLANDA, G., Il m.p. «Apostolos suos» sulle conferenze dei vescovi, Periodica de re canonica 88 (1999) 609-657.

GuTIÉRREZ, J. L., L'attività normativa delle Conferenze episcopali, en Ius in vita et in missione ecclesiae, Acta Symposii Internationalis Iuris Canonici: ocurrente $\mathrm{X}$ anniversario promulgationis Codicis iuris canonici diebus 19-24 aprilis 1993 in Civitate Vaticana celebrati, Libreria Editrice Vaticana, Città del Vaticano 1994, 605-624.

HAMER, J., La responsabilité collégiale de chaque évêque, Nouvelle revue théologique 105/5 (1983) 641-654.

INCITTI, G., Prospetive giuridiche sull'esercizio della sinodalità, en L. BALDISSERI (ed.), A cinquant'anni dall'«Apostolica Sollicitudo», cit., 369-395.

Komonchak, J. A., On the authority of Bishop's Conferences, America 12-IX1998, 7-10.

LÉgrand, H. - ManZanares, J. - García y García, A. (eds.), Naturaleza y futuro de las conferencias episcopales. Actas del coloquio internacional de Salamanca, 3-8 enero 1988, Departamento de Publicaciones de la Universidad Pontificia, Salamanca 1988.

Manzanares, J., Las conferencias episcopales en el nuevo Código de Derecho Canónico, en G. Barberini (a cura di), Raccolta di scritti in onore di Pio Fedele, I, Perugia 1984, 513-531.

-, Reflexiones sobre el documento «Estatuto teológico y jurídico de las conferencias episcopales», Revista española de derecho canónico 46 (1989) 189-202.

-, Las conferencias episcopales. Entre la inquietud y la esperanza, en F. R. AZNAR GIL (ed.), Magister canonistarum. Estudios con motivo de la concesión al prof. $d r$. D. Urbano Navarrete, S.I., del doctorado honoris causa, Publicaciones Universidad Pontificia de Salamanca, Salamanca 1994, 85-110.

Miralles, A., Le conferenze dei vescovi: lettura teologica del motu proprio «Apostolos suos», en IDEM, «Pascete il gregge di Dio». Studi sul ministero ordinato, Edizioni Università della Santa Croce, Roma 2002, 105-144.

MIRAS, J., Fundamentación y naturaleza jurídica de las conferencias episcopales: sugerencias para una reflexión sobre el método, en La Synodalité, vol. II, 529-534. 
Montan, A., Le conferenze episcopali, Credere oggi 34 (2014) 44-61.

ORLANDIS, J., Función bistórica y eclesiológica de los concilios particulares, en La Synodalité, vol. I, 289-305.

Pagan, A., Conferenze episcopali. I lavori del coetus «de sacra Hierarchia» (19661983), Marcianum Press, Venezia 2012.

PerLasca, A., La potestas legislativa del vescovo diocesano nelle conferenze episcopali, Quaderni di diritto ecclesiale 20 (2007) 145-155.

Rivella, M., Decisioni e dichiarazioni delle Conferenze episcopali, Quaderni di diritto ecclesiale 9 (1996) 421-432.

SCHICKENDANTZ, C., La reforma de la Iglesia en clave sinodal. Una agenda compleja y articulada, Teología y Vida 58/1 (2017) 35-60.

SсHмітz, H., Bischofskonferenz und Partikularkonzil. Rechtsinstitutionen unterschiedlicher Natur, Struktur und Funktion, en H. MüLlER - H. J. POTTMEYER (eds.), Die Bischofskonferenz. Theologischer und jurisdischer Status, Patmos Verlag, Düsseldorf 1989, 178-195.

—, Neue Normen für die Bischofskonferenzen. Kanonistische Anmerkungen zum M.P. «Apostolos suos» vom 21. Mai 1998 und zum Schreiben der Kongregation für die Bischöfe vom 13. Mai bzw. 21 Juni 1999, Archiv für katholisches Kirchenrecht 169 (2000) 20-34.

SZABÓ, P., Possibili sviluppi della sinodalità: proposizioni orientali, en L. BALDISSERI (ed.), A cinquant'anni dall'«Apostolica Sollicitudo», cit., 125-135.

—, Il Sinodo episcopale della Chiesa patriarchale in raffronto alla Conferenza episcopale: possibilità e limiti di una «osmosi» tra i due istituti, en G. RUYSSEN (ed.), Il diritto orientale a cinquant'anni dal Concilio Vaticano II, Atti del Simposio di Roma, 23-25 aprile 2014, Orientalia Christiana, Roma 2016, 335-370.

VALDRINI, P., Promotion et limites de l'exercise de la synodalité dans l'Église catholique, Quaderni di Diritto e politica ecclesiastca, n. 1, aprile 2017, 128-139.

VIANA, A., Estructuras personales y colegiales de gobierno. Con referencia especial al problema de la movilidad humana y de la diáspora de los católicos orientales, Folia Canonica 7 (2004) 7-48.

-, Colegio, en J. OtAduy - A. Viana - J. SEDano (eds.), Diccionario general de derecho canónico, Thomson Reuters-Aranzadi, Cizur Menor 2012, vol. II, 215-225.

-, Conferencia episcopal, ibid., vol. II, 484-490.

-, El principio de la colegialidad en la Iglesia, en L. M. CALleja - M. Rovira (eds.), Gobierno institucional. La dirección colegiada, Eunsa, Pamplona 2015, 139-159. 
—, Sinodalidad y derecho canónico, Estudios eclesiásticos 92 (2017) 683-701.

VILLAR, J. R., La naturaleza de las conferencias episcopales y la carta «Apostolos suos», Scripta theologica 31 (1991/1) 115-137.

-, Fundamentos teológicos de las conferencias episcopales, Anuario de derecho canónico 6 (2017) 119-139.

Winterkamp, K., Die Bischofskonferenz zwischen «affektiver» und «effektiver Kollegialität», Lit Verlag, Münster 2003.

ŽUŽEK, I., Un Codice per una varietas Ecclesiarum, en S. GHERRO (ed.), Studi sul Codex Canonum Ecclesiarum Orientalium, Cedam, Padova 1994, 3-31.

—, Understanding the Eastern Code, Pontificio Istituto orientale, Roma 1997. 
COMENTARIOS Y NOTAS 
